\title{
The effect of type of company doing home delivery during a pandemic on consumers' quality perceptions and behavior
}

\author{
Reza Movarrei \\ Marketing, Hanken School of Economics, Helsinki, Finland \\ Sara Rezaee Vessal \\ Operations Management, ESSEC Business School, Cergy, France \\ Saeedeh Rezaee Vessal \\ Marketing, Paris School of Business, Paris, France, and \\ Jaakko Aspara \\ Marketing, NEOMA Business School, Reims, France
}

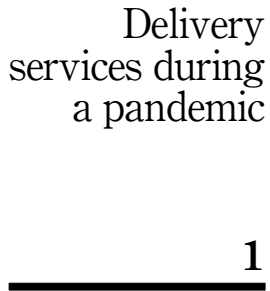

Received 20 August 2020

Revised 3 February 2021 22 June 2021

13 August 2021

16 September 2021

Accepted 5 October 2021

\begin{abstract}
Purpose - In the COVID-19 pandemic, consumers increasingly opt for, or are forced to, use home delivery services. The authors study retailers' decisions regarding "delivery mode", which is about outsourcing (vs. insourcing) the delivery service to a traditional delivery company or an unbranded carrier and its effects on consumers' perceived overall quality, perceived hygienic quality, and subsequently, willingness to stay with the firm beyond the pandemic.

Design/methodology/approach - A pre-test, an experiment and a post-test were conducted with participants from the UK (Total $N=380$ ).

Findings - The results of this study show that (1) in a pandemic, perceived hygienic quality overshadows perceived service quality as a key determinant of consumers' choices, and (2) while consumers have a relatively negative view of the hygienic level of unbranded carriers, they do not differentiate between traditional delivery carriers and retailer-branded carriers. Thus, they are equally interested in using the services of the latter ones. Originality/value - This study shows that during a health crisis, consumers change their hierarchy of motivations to reflect the new protection motivations. The authors usher perceived hygienic quality as a variable that should be seriously considered as both a tactical and a strategic variable affecting the attractiveness of alternative home delivery methods and consumers' intentions to continue using them after the pandemic.
\end{abstract}

Keywords Last-mile delivery, Retail, COVID-19, Quality perception, Hygienic quality

Paper type Research paper

\section{Introduction}

Last-mile delivery (LMD) affects consumers' perceptions of delivery service quality (Huang et al., 2009) and determines consumers' satisfaction with the delivery service [1] to a large

C Reza Movarrei, Sara Rezaee Vessal, Saeedeh Rezaee Vessal and Jaakko Aspara. Published by Emerald Publishing Limited. This article is published under the Creative Commons Attribution (CC BY 4.0) licence. Anyone may reproduce, distribute, translate and create derivative works of this article (for both commercial and non-commercial purposes), subject to full attribution to the original publication and authors. The full terms of this licence may be seen at http://creativecommons.org/licences/by/4.0/ legalcode

Funding: The authors are grateful for a research grant (16-9401) of the Finnish Foundation for Economic Education (Liikesivistysrahasto) which supported this work. The authors would also like to thank the three anonymous reviewers for their comments that assisted us in strengthening the work.

Declarations of interest: Other than the above-mentioned grant, none. The funding organization has not been involved in or influenced the research (choice of specific topic/variables, methodology, data gathering, analysis, etc.) in any ways whatsoever.

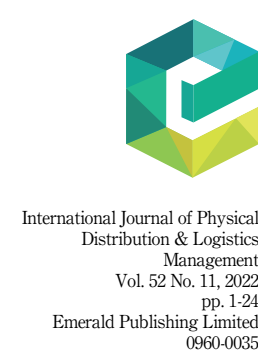

DOI 10.1108/IJPDLM-08-2020-0272 
IJPDLM 52,11

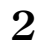

extent (Thirumalai and Sinha, 2005), which subsequently has a significant impact on retailer's image (Vakulenko et al., 2019). Therefore, the choice of LMD arrangement is one of the most substantial decisions for retailers (Esper et al., 2003; Murfield et al., 2017).

Retailers balance their resources to optimally address the demand for different modes of delivery and specifically home delivery services (Vazquez-Noguerol et al., 2020). However, in situations like the COVID-19 pandemic, whereby consumers are mandated to respect social distancing and even lockdowns, retail companies need to rapidly create or expand their home delivery capacities and options (See for example Rigby, 2020; Melton, 2020) [2], in many cases by choosing new business partners.

While the expansion of home delivery services through partnerships may be required only for a short time (i.e. during the pandemic), we argue that its effects on consumers' quality perceptions and behavior may span even beyond the pandemic. With the consumers shift from in-store shopping to online shopping and home delivery services, the means of delivery (carriers, personnel, etc.) become the new interface and the contact point between the retailer and the consumer.

Therefore, choice of the delivery partner (signaled to the consumers through brand visibility) may affect consumers' perceptions of quality of home-delivery service and certain aspects of quality of the delivered products - including hygienic quality. Such perceptions of quality in turn would determine consumers' willingness to stay with the retailer for future purchases (Cui et al., 2020; Eisingerich and Bell, 2008).

Additionally, two factors boost the habit-formation in consumer behavior during the lockdown. First the length of the new situation (e.g. COVID-19), which could last for a relatively long period of time (well over a year), providing a rather large time-window for habit formation and stabilization (Sheth, 2020). Second, many consumers are trying homedelivery services for the first-time during the pandemic and are at the point of forming their initial perceptions. Such initial perceptions and the resulting behaviors often last for a relatively long time (Imprinting theory, Marquis and Tilcsik, 2013). Thus, the retail firm's decisions about the home delivery options during the pandemic may affect the retailer's business way beyond the pandemic.

Despite the acuteness of this business challenge - which can be seen as an opportunity too-for retailers, to the best of our knowledge, this it has remained untouched from the academic perspective. We focus on three types of home delivery modes which defer from each other in terms of how the retail company's brand vs. its home delivery partner's brand appear to the end consumer during the home delivery, via visual cues such as logos on uniforms and delivery vans (Sink and Langley, 1997; Selviaridiss and Spring, 2007; Cho et al., 2008).

The first mode we considered is the one wherein (1) the delivery service personnel and equipment show only the retailer's brand (e.g. retailer-branded carriers or uniforms). The second mode is the one wherein (2) a specialized delivery company's own brand is visible during the home delivery (e.g. UPS delivering for IKEA). Finally, the third option is the one wherein (3) the delivery personnel and equipment are unbranded carriers, such as when peer consumers or entrepreneurs are employed, via smart phone apps, to take care of the last-mile deliveries to consumers.

We conducted a pre-test, an experiment and a post-test with a total of 380 participants from the UK We observed that consumers' intention to use the home delivery services after the pandemic is higher for delivery done by (1) retailer-branded delivery mode and (2) specialized delivery company-branded mode rather than (3) unbranded mode. Further, perceived hygienic quality (rather than overall service quality) determines consumers' intention for using home delivery service after the pandemic. Moreover, this latter effect is more pronounced for the first-time users compared to the existing users. 
Beyond contributing to a few bodies of literature (i.e. LMD strategies, brand visibility in service sector and service business transformation during the pandemic), we intended to make this research a starting point for academics who may be interested in studying the phenomenon with field studies and big data, as well as managers who may be keen to assess their business's situation using their own data.

\section{Theory and hypothesis development}

\subsection{Home delivery modes}

Home delivery is a critical element in any online retailing business (Lim et al., 2018). For consumers, perception of the entire delivery process is, largely, formed based on this final contact point (Kaswengi and Lambey-Checchin, 2019). Consumers' intention to repeat using home delivery services is often a function of their prior satisfaction with it (Hellier et al., 2003; Antwi, 2021; Mensah and Mensah, 2018), which is a result of consumers' perceptions of delivery service quality (Vakulenko et al., 2019; Kaswengi and Lambey-Checchin, 2019). Therefore, design and arrangement of the delivery services is a strategic challenge for online retailers (Murfield et al., 2017).

For the home delivery, retail companies mainly rely on either their own delivery service units, or alternatively, specialized outsourced delivery companies (Sink and Langley, 1997; Selviaridiss and Spring, 2007). A recent addition to the latter type-which sometimes is considered a type by its own-is the platform-based crowd logistics where peers are recruited on a need-based principle, via a platform (e.g. a mobile application) to do home delivery services for a retailer (Kunze, 2016; Mangiaracina et al., 2019; Devari et al., 2017). These peers are typically consumer-entrepreneurs owning vans, providing LMD services to retail companies as well as platform providers (e.g. Uber Eats). Crowd-sourced logistics solutions are increasingly being used to cover for the fluctuations in the demand (Wang et al., 2016). Recently, this solution caught the attention of practitioners (e.g. retailers) facing the unprecedented logistics challenges during the pandemic.

In retailer's own delivery, the retailer's brand logo is visible on the uniforms of the service personnel as well as on the delivery carriers-even if they are rented/hired from a third party. The carriers and personnel of the specialized delivery companies usually operate under a different brand than the retailer's (e.g. UPS, Fedex, etc.) while the crowd-sourced delivery carriers and personnel usually do not carry any brand (Business Insider Intelligence, 2019). In these last modes, even though a retailer may not be directly involved in the LMD of the product, its image will still be significantly affected by the quality of the LMD (Esper $e$ al., 2003; Vakulenko et al., 2019).

Previous research has mostly focused on the first two modes of home delivery, suggesting that the retailers' choice between them may influence consumers' perceptions of the delivery service, online shopping and the retailer (Kalyanam and McIntyre, 2002; Jie et al., 2015). The perceived differences between these two modes are often related to the differences in the types of resources and facilities that they may have (Lebeau et al., 2015).

However, these perceived differences are eventually related to the recognition and perception of a visible brand carried by the delivery personnel and carriers. In other words, perceived technical capabilities and resources of the delivery carrier is a consequence of the brand recognition and awareness (Murfield et al., 2017; Esper et al., 2003). This is because, from the consumers' point of view, the brand logo carried by the delivery agent is the sole clue to the identity of the agent. Brands with higher recognition (retailer and/or the delivery company) often generate more favorable perceptions (Render and O'Connor, 1976; Chu et al., 2005; Sahin et al., 2012) and lead to higher levels of satisfaction and repurchase intentions (Esper et al., 2003). 
IJPDLM 52,11

For this reason, even when the LMD services are outsourced, an important strategic decision remains; whether to use a delivery agent that carries the retailer's brand logo, or to use a delivery agent that carries the brand of a reputable delivery company. In both cases, the actual carrier may not be owned by the owner of the brand shown to the consumers.

\subsection{The challenges of the pandemic situation}

Relevant aspects that characterize the decision-making setting for retail companies and practitioners during a pandemic situation can be classified as: (1) potential need to cooperate with new business partners, (2) number of consumers who use home delivery service for certain products for the first time and (3) sensitivity of the situation and the hygienic issues that are concerning consumers.

Regarding the first aspect, while some firms might have the capacity to address the increasing demand for home delivery by collaborating with their current business partners, many firms are not reactive to this extent. Some examples of the businesses that are vital in the daily lives of people and must function mainly through online ordering and home delivery during the lockdown, include grocery retailers, pharmacies and children's/pets' accessory retailers. The COVID-19 pandemic has witnessed the demand for this kind of delivery to skyrocket, in some cases growing by a full order of magnitude (according to ShipBob's daily statistics (2020) updates, monthly sales of baby product in the UK increased by $694 \%$ during March 2020). This forced several retailers to quickly engage in new delivery partnerships (Rigby, 2020).

Considering the second factor, during the pandemic a significant number of consumerswho, under normal conditions, would rarely utilize home delivery services - were suddenly willing (or forced) to use them (Bain \& Co report 2020). According to a survey by Gordon Haskett Research Advisors on March 13, 2020, one-third of American consumers said that they have tried online grocery shopping over the preceding week, and among those, a whopping $41 \%$ were doing so for the first time (Boyle, 2020). While these new customers are important contributors to the surge of the home-delivery demand discussed above, they may also be more suggestible to various cues while they are exposed to different delivery modes, as they are just about to form their perception regarding the quality of the delivery service and the service providers (Marquis and Tilcsik, 2013; Agag and El-Masry, 2017).

As for the third factor, during a pandemic consumer may (naturally) be more sensitive and vigilant towards certain aspects of services. More specifically, exposure to a threat and the desire to avoid the potential negative outcomes of it would motivate taking appropriate protective measures (Rogers, 1975; Maddux and Rogers, 1983; Floyd et al., 2000). For these reasons, firms need to pay careful attention to the choice of home delivery mode during the pandemic. The last two factors may also extend the effect of delivery mode on consumers' behavioral intentions over a relatively long period of time (Marquis and Tilcsik, 2013).

\subsection{The effect of home delivery mode on hygienic quality perceptions}

Hygienic quality describes and characterizes the way cleanliness of a service environment is perceived by consumers (Vos et al., 2019; Yu et al., 2021). Hygienic quality perception is a subdimension of general service quality perceptions, and a few items within most frequently used service quality scales (e.g. SERVQUAL and SERVPERF) are dedicated to it. Hygienic quality perceptions as a function of type of company providing a service have rarely been studied. However, consumers' trust in the service provider's ability to offer a high-quality service - in conformity with the consumers' expectations - may act as a proxy for hygienic quality perceptions. This is because hygienic quality perception is a sub-dimension of general quality perception (Carrillat et al., 2007) and in the absence of the evidence to the contrary, it is natural to assume that reputation and perceived trustworthiness of a company would increase all sub-dimensions of perceived quality at the same time. 
In this regard, choosing a reputable delivery partner is shown to increase consumers' trust in the quality of a retailer's services (Wolfinbarger and Gilly, 2003), especially in risky situations because trust is interwoven with risk and both are based on perceptions of quality (Jarvenpaa et al., 2000). Particularly in a pandemic, trust in the competency of a retailer to arrange proper delivery would help mitigate the higher level of uncertainly and health risks (Doney and Cannon, 1997) and consequently may lead to a relatively long-term effect on consumers' preferences and behavioral intentions. Because mode of the home delivery is communicated with the consumer through the brand carried by the delivery personnel/ carriers, we expect that brand recognition for certain types of home delivery modes would lead to a more positive general and hygienic quality perceptions (Sugiharto et al., 2019).

We expect that during the pandemic (1) the retailer's own delivery service (or the outsourced ones carrying the retailer's name) and (2) the services of specialized delivery companies, would lead to both greater general quality and greater hygienic quality perceptions compared to the perceptions that consumers would form when the retailer uses (3) the services of unspecialized, unbranded service providers. A retailer that performs its own home delivery services during the peak demand (e.g. during a pandemic), shows off its capabilities to take the entire responsibility of the delivery services under any circumstances (Heinonen and Strandvik, 2020; Boyer and Frohlich, 2006). Consumers may perceive such a resourceful retailer as the one that most likely provides a delivery with high levels of service quality as well as hygienic quality.

Similarly, when a retailer delivers its products via a specialized delivery company, the aspect of costly signaling is still present (Connelly et al., 2011; Li et al., 2015). While the specialized delivery companies would be perceived to have good capabilities in making high quality professional deliveries (Morash et al., 1996), their services are also perceived to be more expensive than crowd-sourced logistics. A retailer's decision to hire a more expensive professional service provider during the pandemic would show the availability of resources that would allow the retailer to use such options. It might also be considered as its intention to take special care of the (hygienic) quality of the delivered products when the consumers are most vulnerable.

In contrast, the unspecialized, unbranded delivery service providers are simply perceived to be both cheaper and to offer relatively lower quality, than the aforementioned ones. Research on personal transportation services and platform companies (Edelman and Geradin, 2015; Kumar and Kumar, 2004) indicates that consumers perceive entrepreneurial drivers (e.g. of Uber, Lyft, etc.) as having lower capability and reliability in delivering highquality service, than specialized delivery companies and drivers. As a result, using the unbranded delivery mode may signal lack of resources to use higher-quality (costlier) options and lack of interest in taking good care of the consumers during the pandemic. Based on the above explanations, we hypothesize:

H1a. Using a retailer-branded or specialized delivery company (rather than an unbranded delivery agent) during the pandemic will be associated with higher perceived hygienic quality.

H1b. Using a retailer-branded or specialized delivery company (rather than an unbranded delivery agent) during the pandemic will be associated with higher perceived service quality.

\subsection{Quality perceptions, hygienic quality perceptions and behavioral motivations}

In general, positive delivery service quality perceptions would lead to higher level of satisfaction and positive attitude towards the delivery service and the retailer (Carlson and O'Cass, 2010), and consequently, would increase consumers' willingness to repurchase from
Delivery
services during

a pandemic

\section{(1)}


IJPDLM 52,11 the same retailer (Sahin et al., 2012). That is, consumers' willingness to trust a service provider for future purchases and deliveries, may be a function of the perceived quality of the delivery service (Eisingerich and Bell, 2008).

The relevance and importance of different aspects of service quality (to consumers) would vary according to the service setting (Rosen and Karwan, 1994). In the normal conditions, different aspects of delivery service quality are associated with different risks of the delivery service, for example, to make sure that the delivery is timely, unflawed and hygienic (VilnaiYavetz and Gilboa, 2010; Lemon and Verhoef, 2016). Consequently, when the likelihood of a specific risk occurrence is higher (e.g. in a health crisis), we would expect consumers to prioritize the corresponding aspect of delivery service quality.

During the pandemic, consumers need to make sure they can acquire the basic daily supplies (e.g. food and medicine) in a timely and hygienic manner. Protection motivation theory (PMT) predicts that, in such circumstances, consumers would change their hierarchy of preferences/motivating factors (i.e. the aspects of service quality that they value the most) to reflect the new protection motivations (Rogers, 1975; Maddux and Rogers, 1983).

PMT suggests that when people are facing a threat, they would assess its severity and their ability to cope with it and consequently decide the way to deal with it (Maddux and Rogers, 1983). Applying PMT, previous studies have investigated consumer behavior facing e.g. norovirus disease prevention in the cruise industry (Fisher et al., 2018), infection control in the hotel industry (Choi, 2019) and restaurant industry (Choi et al., 2019).

PMT is formulated to predict behavioral intentions rather than actual behaviors - which may depend also on a range of external conditions and environmental factors (Rogers, 1975; Floyd et al., 2000). PMT has six assumptions under which the protection motivation will form: (1) the threat to health is severe, (2) individual facing the threat feels vulnerable, (3) the adaptive response is believed to be an effective means for averting the threat; (4) the person is confident in his/her abilities to successfully complete the adaptive response; (5) the rewards associated with the maladaptive response are small, and (6) the costs associated with the adaptive response are small.

In the pandemic stage of a serious infectious disease (like COVID 19), all the abovementioned assumptions hold. That is, the threat is serious, and the entire population feels vulnerable, hygiene and safety measures are often doable and effective for the average person, and the benefits of noncompliance and costs of compliance with preventive guidelines and suggestions are relatively small. Therefore, PMT predicts that consumers would prioritize their protection from the disease over other motivations (Rogers, 1975; Milne et al., 2000).

Therefore, we predict that those aspects of delivery service quality that are related to the ongoing health risk would become more important decision criteria. In other words, hygienic quality in addition to (and maybe more strongly than) service quality would determine whether repurchasing from the retailer (with home-delivery) would be an example of adaptive (vs. maladaptive) response. Therefore, we hypothesize:

H2a. Perceived hygienic quality is associated with greater intention to continue using home delivery service after the pandemic.

H2b. Perceived service quality is associated with greater intention to continue using home delivery service after the pandemic.

Figure 1 shows the conceptual model of our research.

A final point is that choice of the delivery partner is communicated with the consumer mainly through brand visibility on e.g. delivery vans, delivery personnel uniform, etc. In this sense, the hypothesis about the delivery carrier type reflects the type of company whose brand is conspicuously used by the carrier. For the consumer, this brand reflects the identity 
of the delivering carrier. Thus, when a reputable brand (of the retailer or the specialized delivery company) is conspicuously used by the carrier, such visibility would translate into perceived hygienic quality, and subsequently, repurchase intention (Sugiharto et al., 2019; Vilnai-Yavetz and Gilboa, 2010; Esper et al., 2003). Summarizing the above discussion, we hypothesize:

H3. Perceived hygienic quality will mediate the relationship between delivery mode and intention to continue using home delivery service after the pandemic.

H4. The effect of perceived hygienic quality on intention to continue using home delivery service after the pandemic will be greater than the effect of perceived service quality on such intention.

\subsection{The moderating effect of previous experience with home delivery services}

In formulating hypotheses H2-H4 we argued that such a health crisis as a pandemic would transform consumers' hierarchy of motivations in favor of protection motivations, and subsequently, would encourage intentions and behaviors that are in conformity with such motivations. However, we also need to acknowledge that consumers have a baseline (i.e. prepandemic in our case) level of motivation for any target behavior (i.e. using home delivery services) based on their previous experience with that behavior. These pre-existing motivations may influence the effect of newly formed motivations (i.e. protection motivations) on the target behaviors.

Consumers who had been frequently using home delivery services before the pandemic have already established their habit. This means that they are satisfied with delivery service quality and do not necessarily need additional (hygiene-related) motivations to continue using these services after the pandemic. While their usage habit is already imprinted, the rest of consumers may be at the point of forming such habits.

A significant number of consumers, who would rarely utilize home delivery services under normal conditions, started using them for the first time during the pandemic (Boyle, 2020). They need additional motivations to continue using these services after the pandemic. For them, protection motivations (hygiene concerns) during a pandemic can provide such additional motivation. For these users, we expect the effect of perceived hygienic quality on intention to continue using these services to be more pronounced. In contrast, frequent users of home delivery services do not need such additional motivations, and thus for them the effect of perceived hygienic quality on intention to continue using home delivery may be modest.

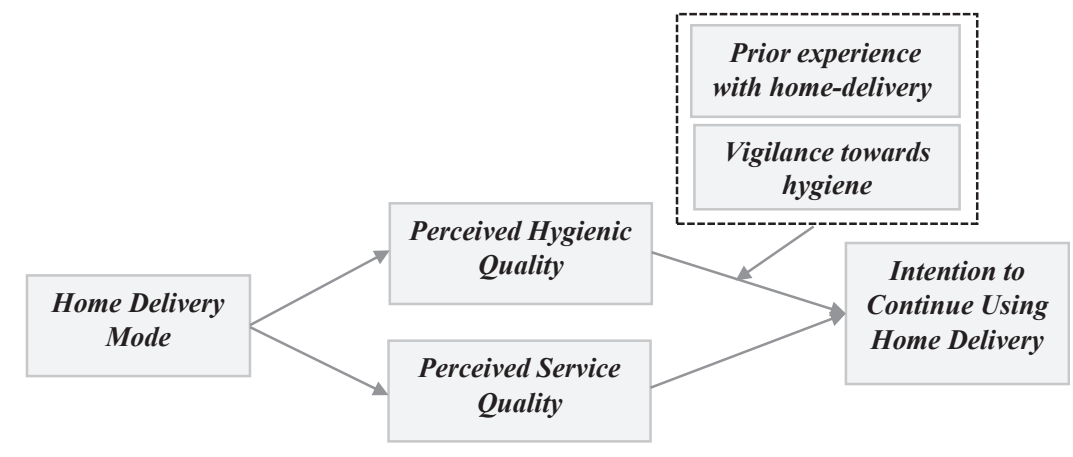

Delivery services during a pandemic

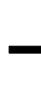


IJPDLM

52,11

8

This is consistent with the imprinting theory (Marquis and Tilcsik, 2013), which argues that, when an individual experiences a sensitive period of transition, a new set of perceptions and behaviors are formed in response to that transition, which are likely to persist for a relatively long time after the transition. In our case, prior infrequent users of home delivery services are experiencing a period of transition in their routines. Not only they are facing all the changes that the pandemic situation and "new normal" are bringing about, but also, they must use a service (home delivery) that is rather new to them. This may make them more sensitive and suggestible (than prior frequent users) to the service quality cues. The resulting behavior (intention to continue using home delivery) in reaction to environmental cues (hygienic quality), would imprint and endure for a relatively long time - after the pandemic (Marquis and Tilcsik, 2013; Agag and El-Masry, 2017).

Furthermore, the pandemic as a health crisis, and the subsequent motivation of consumers to take appropriate protective measures (Rogers, 1975; Milne et al., 2000; Floyd et al., 2000), would make a group of consumers (not necessarily the first-time users of home delivery services), extra vigilant and observant towards the hygienic issues - in our case the hygienic quality of the home delivery. This period of extra-vigilance may also act as the initial abrupt transition period for these consumers and make them more imprintable (Ogden and Hills, 2008). We expect these consumers to be more suggestible to hygienic quality perceptions. Therefore, we hypothesize:

H5a. Frequency of using home delivery services before the pandemic negatively moderates the relationship between perceived hygienic quality and intention to continue using home delivery service after the pandemic.

$H 5 b$. Vigilance towards hygiene positively moderates the relationship between perceived hygienic quality and intention to continue using home delivery service after the pandemic.

\section{Methodology}

\subsection{Experiment overview}

We ran a pre-test, an experiment and a post-test. In the pre-test, we established that during the pandemic overall quality is not a good predictor of consumers' repurchase intentions - as it used to be in the pre-pandemic times. This set the scene for the experiment, which examines whether hygienic quality can be such a predictor. We tested whether hygienic quality and overall quality mediate the relationship between delivery mode and consumers' intention to continue using home delivery after the pandemic. We also tested whether the link between hygienic quality and repurchase intention is stronger for prior-infrequent consumers. Finally, in the post-test we did a realism check and ruled out the alternative explanation that the results of the main experiment may have been due to the mere presence of the brand and not due to the mode of the delivery as argued.

\subsection{Variables and measurement}

In the experiment (and the pre-test), we used a between subject design, with a scenario related to online shopping/home delivery during the pandemic. A total of 380 people participated in the pre-test, experiment and the post-test. All the participants were living in the UK and were also members of the Prolific Academic participant pool (www.prolific.ac). The Prolific Academic pool of participants has been empirically tested and is recognized for good data quality (Peer et al., 2017).

The studies were designed in Qualtrics platform, and participants were compensated for attending them ( $£ 0.8$ for the experiment and the pretest, $£ 0.7$ for the post-test). The three 
studies were run in a chronological order (not in parallel), and participants of each study were excluded from the other two studies (e.g. those taking part in the pre-test were excluded from the subject-pool for the main experiment and the post-test). The variables and measures are as follows; please consult Table 1 for the details of items, as well as the reliability statistics.

3.2.1 Independent variable (delivery mode). This variable was manipulated to create the 3 conditions of a between subject experimental design: (1) retailer-branded carrier/personnel, (2) a delivery company-branded carrier/personnel or (3) unbranded carrier/personnel.

3.2.2 Dependent variable. This variable was measured by 1 item (adopted from Venkatesh et al., 2003) covering consumers' intention to continue using home delivery services after the pandemic.

3.2.3 Mediator 1 (perceived hygienic quality of the delivery service). Mediator 1 was measured by 10 items (adopted from Vos et al., 2019) measuring the perceived hygiene of the delivery process, personnel and the delivered products. The items (Table 1) were measured on a 7-point Likert scale, ranging from strongly disagree to strongly agree.

3.2.4 Mediator 2 (perceived overall quality of the delivery service). SERVPERF scale (adopted from Cronin and Taylor, 1992; Dabholkar et al., 1996) was used to measure different aspects of perceived service quality: 22 items (Table 1) were measured with 7-point Likert scale, ranging from strongly disagree to strongly agree.

3.2.5 Moderator 1 (frequency of using home delivery services before the pandemic). This variable was measured by one item: "Before the coronavirus lockdown, how frequently were you using home delivery services (of any store)?" It was measured on a 7-point Likert scales, ranging from very rarely to very frequently.

3.2.6 Moderator 2 (vigilance towards hygiene). This variable was measured by one item, asking whether participants would consider themselves to be more vigilant and observant of the recommendations of health authorities than the average person: "Compared to the average (person), would you consider yourself to be more cautious and observant of the recommendations of health-authorities about coronavirus spread?' (measured on a 7-point Likert scale, ranging from definitely less observant to definitely more observant).

3.2.7 Control variables. (1) Frequency of using online shopping before the pandemic, frequency of using (2) online shopping and (3) home delivery services during the pandemic (all three questions measured on 7-point Likert scales, ranging from very rarely to very frequently). Four demographic variables (age, gender, education, monthly budget before the pandemic) were also included.

\subsection{Pre-test}

3.3.1 Procedure and design. The aim of the pre-test was to check whether, during a health crisis, overall quality can still be a good predictor of consumers' behavioral intentions - as it used to be in the pre-pandemic times. One hundred fifty adults (96 women; Mage $=32.26$ years, $\mathrm{SD}=10.85$ ), completed the pre-test. A three-conditions (type of delivery mode: retailer-branded versus delivery company-branded versus unbranded) between-subject design was used. The pre-test was framed as a survey on daily life during the coronavirus pandemic. After a welcome message, participants read a scenario in which they were asked to assume that they have just bought (online) a few personal items from a local chain's website and have opted for the home delivery services. Depending on the experimental condition, the actual delivery mode was described to be performed by (1) retailer-branded carrier/personnel, (2) delivery company-branded carrier/personnel or (3) unbranded carrier/personnel. Then, participants answered a number of questions about (1) the perceived quality of the delivery service (based on SERVPERF) and (2) their intention to continue using home delivery services after the pandemic.
Delivery
services during

a pandemic 
IJPDLM 52,11

10
Measurement items

Cronbach's $\alpha$

Mediators

Perceived quality of service (SERVPERF)

(Adopted from Cronin and Taylor, 1992; Dabholkar et al., 1996)
The following set of statements relate to your feelings about the home delivery option that you just extent to which you believe the delivery company

\section{Table 1.}

Scales used in the experiments and their items read about. For each statement, please show the has the feature described by the statement. Choosing seven means that you strongly agree that the delivery company has that feature and choosing one means that you strongly disagree. You may choose any number in the middle as well to show how strong your feelings are. There are no rights or wrong answers - all we are interested in is a number that best shows your perceptions about the home delivery option described earlier

(1) The vehicles used for this home delivery would look modern

(2) The vehicles used for this home delivery would be visually appealing

(3) The person who does the home delivery would appear well-dressed and neat

(4) The appearance of the vehicles used for this home delivery would be keeping with the type of service provided

(5) When home delivery is promises to be done by a certain time, it will be done so

(6) When you have problems with the delivery, these delivery people will be sympathetic and reassuring

(7) These delivery people would be dependable

(8) These delivery people would provide their services at the time they promise to do so

(9) These delivery people would keep their records accurately

(10) They do not tell their customers exactly when the delivery will be performed

(11) You do not receive prompt service from them

(12) They are not always willing to help customers

(13) They are too busy to respond to customer requests promptly

(14) You can trust them

(15) You can feel safe in your transactions with them

(16) They are polite

(17) They get adequate support to do their job well

(18) They do not give you individual attention

(19) They do not give you personal attention

(20) They do not know what your needs are

(21) They do not have your best interests at heart

(22) They do not have operating hours convenient to all their customers 


\section{Variable}

Perceived hygienic quality

(Adopted from: Vos et al., 2019)

\section{Measurement items}

(1) The delivery person would look organized and orderly

(2) The delivery person would follow the principles of hygiene

(3) The delivery person would look well-dressed

\section{Dependent variable}

Intention to continue using home delivery (Adopted from: Venkatesh et al., 2003)

\section{Moderators}

Prior experience with home delivery

Vigilance towards hygiene

\section{Control variables}

Frequency of online shopping

Demographic

\section{Realism and plausibility check}

Realism check

Plausibility check and neat

(4) The delivery person would look clean

(5) The delivery person would follow the safety instructions set forth by the public health authorities

(6) The items would look neat

(7) The items would look organized and orderly

(8) The items would look clean and free of dust, fingerprintsetc.

(9) The items would look hygiene and virus-free

(10) The items would smell clean and hygienic

If the above scenario actually happens to you, would you be willing to continue using home delivery services of the store after the pandemic too?

Before the coronavirus lockdown, how frequently were you using home delivery services (of any store)? Compared to the average (person), would you consider yourself to be more cautious and following the recommendations of health-authorities about coronavirus spread?

\section{Frequency of online shopping}

(1) Before the coronavirus lockdown, how frequently were you doing online shopping (in any store)?

(2) During the coronavirus lockdown, how frequently are you doing online shopping (in any store)?

Frequency of using home delivery services

During the coronavirus lockdown, how frequently are you using home delivery services (of any store) Gender, Age, Education, monthly budget before the pandemic situation

(1) The situation described in the scenario was quite realistic

(2) I had no difficulty imagining myself in the situation described in the scenario

How confident are you in your response to the previous question (your willingness to continue using home-delivery services of the shop? 
IJPDLM 52,11

\section{2}

3.3.2 Results. We used PROCESS macro for SPSS (Hayes, 2017; mediation model 4) with the delivery mode as the independent variable, perceived quality of the delivery service (SERVPERF) as the mediator and intention to continue using home delivery service after the pandemic as the dependent variable. In the analysis, we did not find the indirect effect of delivery mode (through perceived service quality) on consumers' intention to continue using the service after the pandemic to be significant $\left(\beta_{\text {delivery-branded }}=0.039,95 \%\right.$ CI: $-0.043-$ $0.017 ; \beta_{\text {retailer-branded }}=0.046,95 \%$ CI: $-0.056-0.018$ ). Breaking down this insignificant effect, we observed the statistically significant effect of delivery mode on perceived overall quality of the home delivery service $\left(\beta_{\text {delivery-branded }}=0.203\right.$; $\mathrm{SE}=0.068 ; p<0.01$; $\left.\beta_{\text {retailer-branded }}=0.241 ; \mathrm{SE}=0.069 ; p<0.01\right)$ and in turn, the insignificant effect of perceived quality of service on consumers' intention to continue using the home delivery service after the pandemic $(p>0.05)$. The direct path for both retailer-branded delivery mode and specialized delivery company-branded mode was only marginally significant $(\phi<0.1)$.

Subsequently, the ANOVA analysis of participants' intention to continue using the home delivery service after the pandemic as a function of delivery mode, yielded a marginally significant main effect $(F(2.143)=2.737, p=0.06)$. However, the pairwise comparisons confirmed that participants who had been served by the unbranded delivery mode $(M=6.32$, $\mathrm{Sd}=0.89$ ) were less willing to continue using this service after the pandemic, compared to the participants who had been served either by specialized delivery company-branded mode $(M=6.62, \mathrm{Sd}=0.70, p<0.05)$, or by the retailer-branded mode $(M=6.63, \mathrm{Sd}=0.53, p<0.05)$. We did not observe a significant difference between the retailer-branded mode and the delivery company-branded mode $(\phi>0.1)$. Additionally, none of the control variables (when included in the analysis) led to any significant change in the results (Table 2).

Therefore, the results of the pre-test support the notion that during a health crisis, perceived service quality would not be a strong predictor of consumers' behavioral intentions. This suggests that in such times consumers value something other than the traditional construct of service quality. In the main experiment we test whether consumers' protection motivations can better explain their behavioral intentions during the pandemic.

\subsection{Main experiment}

The results of pretest suggest that retailer-branded delivery mode and specialized delivery company-branded mode enjoy more favorable evaluations of overall service quality during a pandemic. However, these overall service quality perceptions may no longer be a strong predictor of such market variables as intention to continue using the service after the pandemic. The near significant direct path in the mediation analysis provides further evidence that a significant part of the effect is not going through the overall service quality as the traditional mediator - that would in normal conditions predict consumers' behavioral intentions (Carrillat et al., 2007).

Therefore, finding a more suitable mediator that would explain the mechanism of the effect during the pandemic is essential. This is because, in practice, many retailers are forced to use the unbranded delivery mode during the pandemic situation and knowledge of

Table 2.

Covariates included in pre-test and the main experiment ( $p$-values)

\begin{tabular}{lcc}
\hline Variables & Pre-test & Experiment \\
\hline Frequency of online shopping before the pandemic & 0.412 & 0.911 \\
Frequency of using home delivery services before the pandemic & 0.305 & - \\
Frequency of online shopping during the pandemic & 0.062 & 0.872 \\
Frequency of using home delivery services during the pandemic & 0.201 & 0.987 \\
Vigilance towards hygiene & 0.654 & -
\end{tabular}


the mechanism of this effect will provide them with a hint about the actions that may improve consumers' reaction toward the unbranded delivery mode. To address this, in the main experiment we tested a parallel mediating model including both overall service quality (SERVPERF scale adopted from Dabholkar et al., 1996) and hygienic quality (adopted from Vos et al., 2019). Further, we tested the hypothesized moderating effects of frequency of using home delivery services before the pandemic and vigilance towards hygiene.

3.4.1 Procedure and design. One hundred fifty adults from the UK (97 women; $M_{\text {age }}=35.64$ years, $\left.\mathrm{Sd}=11.79\right)$, completed the study which was run a few days after the pre-test (in the Spring of 2020). A three-conditions (delivery mode: retailer-branded versus delivery company-branded versus unbranded) between-subject design was used.

At the time of running the experiment, the entire Europe was involved in the pandemic situation and a nationwide lockdown was ongoing in the UK. The procedure was designed in Qualtrics platform. In the first screen, participants saw a welcome message and a brief description of the purpose of the experiment. They were told that, in the next pages they will read a scenario about their purchasing habits during the pandemic and will answer a few questions about it.

Then, depending on the experimental condition of delivery mode, one of the three types of carriers was randomly presented to each participant through the scenario (see Appendix for the details of the scenarios). To avoid reminding participants about the delivery modes other than the one presented to each of them in the scenario, we used an open (text-entry) question as the manipulation check: "Please describe the type of carrier that delivered your items in the scenario". In total, 147 participants $(98 \%)$ provided the correct answer indicating that the manipulation had been successful. The three participants who failed the manipulation check were removed from the analysis. This removal did not correspond to any significant change in the results.

Then, participants answered five sets of questions about (1) the mediators: perceived hygienic quality of the delivery service (adopted from Vos et al., 2019) and perceived overall quality of the delivery service (SERVPERF scale, adopted from Dabholkar et al., 1996), (2) dependent variable: their intention to continue using home delivery service after the pandemic (adopted from Venkatesh et al., 2003), (3) moderators: frequency of using home delivery services before the pandemic and observance of hygienic recommendations and finally (4) control variables and demographic variables mentioned earlier.

3.4.2 Results. The analysis was conducted using PROCESS macro for SPSS (Hayes, 2017; moderated mediation model 14) with the delivery mode as the independent variable, perceived service quality and perceive hygienic quality as the mediators, intention to continue using home delivery service after the pandemic situation as the dependent variable and frequency of using home delivery services before the pandemic and vigilance towards hygiene as moderators.

The analysis revealed that using a specialized delivery company or insourcing the delivery (compared to unbranded mode as the baseline) has a significant indirect effect on consumers' intention to continue using home delivery services after the pandemic. This effect was mediated by perceived hygienic quality $\left(\beta_{\text {delivery-branded }}=0.331,95 \%\right.$ CI: $0.116-0.621$; $\beta_{\text {retailer-branded }}=0.443,95 \%$ CI: $0.184-0.783$ ) rather than perceived overall service quality $\left(\beta_{\text {delivery-branded }}=-0.054,95 \%\right.$ CI: $-0.149-0.014 ; \beta_{\text {retailer-branded }}=-0.047,95 \%$ CI: -0.129 0.012). Neither of the direct effects of delivery modes on consumers' intention to continue using the home delivery service after the pandemic were significant in the presence of mediators $(p>0.1)$. Therefore, $\mathrm{H} 3$ is supported.

The indirect effects consist of the statistically significant effect of delivery mode on perceived hygienic quality $\left(\beta_{\text {delivery-branded }}=0.631 ; \mathrm{SE}=0.143 ; p<0.01\right.$; $\beta_{\text {retailer-branded }}=0.845 ; \mathrm{SE}=0.142 ; p<0.01$ ) and perceived overall quality

Delivery services during a pandemic 
IJPDLM 52,11

\section{4}

$\left(\beta_{\text {delivery-branded }}=0.265 ; \mathrm{SE}=0.086 ; p<0.01 ; \beta_{\text {retailer-branded }}=0.227 ; \mathrm{SE}=0.085 ; p<0.01\right)$ and in turn the effect of perceived hygienic quality $(\beta=0.524 ; \mathrm{SE}=0.096 ; p<0.01)$ on consumers' intention to continue using home delivery services. Replicating the results of the pretest, the effect of perceived overall quality on consumers' intention to continue using home delivery service after the pandemic was not significant $(\phi>0.1)$. Therefore, H1a, H1b, H2a and H4 receive support, while $\mathrm{H} 2 \mathrm{~b}$ does not.

The positive effect of using retailer-branded delivery mode on the statistically significant mediator (i.e. perceived hygienic quality) was slightly larger than the positive effect of using delivery-branded mode. Figure 2 shows the main effect of delivery mode on participants' intention to continue using home delivery services after the pandemic (the dependent variable) as well as their perceptions of overall service quality (mediator 1) and hygienic quality (mediator 2).

The analysis of participants' intention to continue using the home delivery service after the pandemic as a function of delivery mode, yielded a main effect $(F(2.146)=8.409, p<0.01)$. Pairwise comparisons confirmed that participants who had been served by the unbranded delivery mode ( $M=6.16, \mathrm{Sd}=1.143)$ were less willing to continue using this service after the pandemic, compared to the participants who had been served either by delivery companybranded mode $(M=6.54$, $\mathrm{Sd}=0.683, p<0.05)$, or by the retailer-branded mode $(M=6.82$, $\mathrm{Sd}=0.388, p<0.01)$. We observed a near-significant difference between the retailer-branded mode and the delivery company-branded mode $(p=0.087)$. Therefore, we find support for $\mathrm{H} 1 \mathrm{a}$ and $\mathrm{H} 1 \mathrm{~b}$, also replicating the results of the pre-test. Additionally, none of the control variables (when included in the analysis) led to any significant change in the results (Table 2).

The results of the moderated mediation analysis revealed a significant effect for the home delivery experience before the pandemic $\left(\beta_{\text {interaction term }}=-0.1264\right.$; $\mathrm{SE}=0.0343$; $p<0.001$; Index of moderated mediation delivery-company $=-0.0724, \mathrm{SE}=0.038,95 \%$

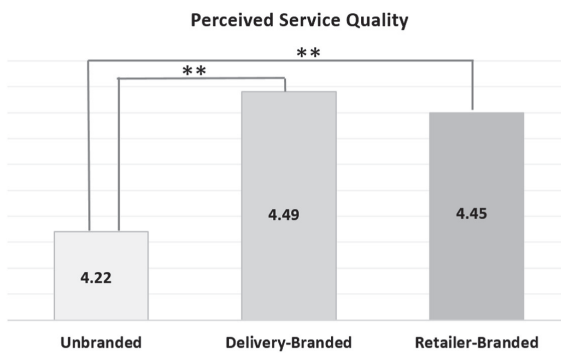

(a)

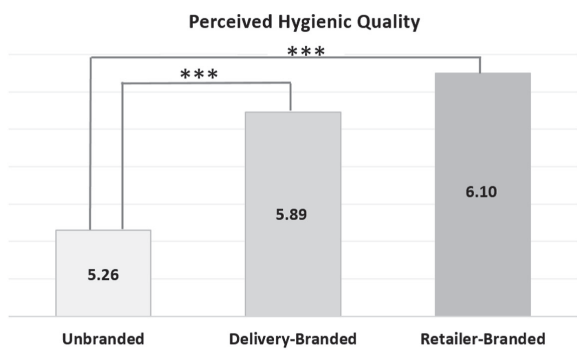

(b)
Figure 2.

Results of the main experiment: effect of delivery mode on (a) Perceived service quality, (b) Perceived hygienic quality and (c) Intention to continue using home delivery (after pandemic)

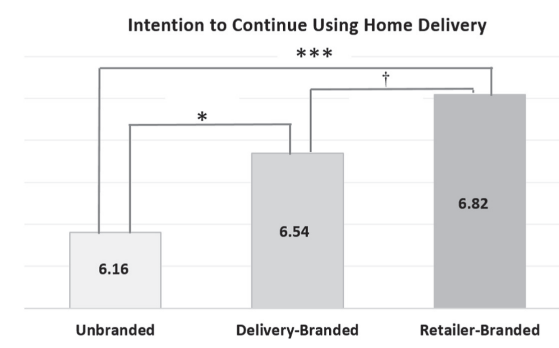

(c)

Note(s): $\uparrow$ significant at $p<0.1, *$ significant at $p<0.05, * *$ significant at $p<0.01$, $* * *$ significant at $p<0.001$ 
CI: $-0.1545--0.0056$; Index of moderated mediation retailer $=-0.097, \mathrm{SE}=0.047,95 \%$ CI: $-0.1920--0.0086)$. More specifically, the effect of hygienic quality perceptions on consumer's intention to continue using home delivery service after the pandemic was stronger when the consumer had little prior experience with home delivery -and thus could be assumed to be more imprintable (Prior experience value $=2: \beta=0.7363$; $\mathrm{SE}=0.1071$; $p<0.001$; when prior experience value $=6: \beta=0.2306$; $\mathrm{SE}=0.1061 ; p<0.05$ ). Finally, the interaction term for vigilance towards hygiene as the second moderator was not significant $(p>0.1)$. Thus, H5a receives support while H5b does not. Delivery
services during
a pandemic

\subsection{Post-test}

The goal of post-test, which used new participants from the same pool of participants as the main experiment, was threefold: (1) to do a realism check (Dabholkar, 1994) on the scenarios. To avoid confounds (as much as possible), these scenarios were brief (about 150 words) and did not contain pictures and names of specific brands. Therefore, it was important to make sure they have been sufficiently realistic and imaginable for the participants. (2) To check the plausibility of the responses given to the dependent variable question and explore how confident of their responses our participants are (Bush et al., 2008).

Finally, (3) to rule out an alternative explanation; that the results of experiments 1 and 2 may have been due to a specific (branded vs. unbranded) comparison and not due to the mode of delivery as we argued. Since we obtained similar results for the retailer branded and delivery company-branded modes (both branded) versus the unbranded mode, we wanted to make sure that merely using a brand (any brand other than these two) would not create the same effect on our dependent variable.

3.5.1 Procedure. Eighty adults ( 51 women; $M_{\text {age }}=31.52$ years, $\mathrm{Sd}=9.73$ ), completed the study. We used a four-conditions between-subjects design in which the delivery mode was manipulated between conditions: (1) retailer-branded carrier/personnel, (2) delivery companybranded carrier/personnel, (3) unbranded carrier/personnel or (4) carrier/personnel carrying a brand not clearly associated with either the retailer or a delivery company (first 3 conditions were identical to those used in the main experiment). The procedure was similar to the main experiment. After the welcome message, one of the above-mentioned four scenarios was randomly presented to each participant.

In the subsequent screens, participants answered a set of questions including (1) one question about their intention to continue using home delivery service after the pandemic (same as the dependent variable question in the main experiment), (2) two questions of a realism check (Dabholkar, 1994) and (3) one question checking the plausibility of the response given to the dependent variable question (Bush et al., 2008). Each item was presented in a separate screen. All items were measured on 7-point Likert scales (See Table 1 for details).

3.5.2 Results. Realism check included two items adopted from Dabholkar (1994). Following the recommendations, we used the average of these two items to study whether our scenarios have been sufficiently realistic. The results (Figure 3) show that participants in all four conditions had considered the scenarios to be relatively realistic and imaginable $\left(M_{\text {retailer }}=5.97\right.$, $\mathrm{Sd}=1.04 ; M_{\text {delivery-company }}=5.86, \mathrm{Sd}=1.24 ; M_{\text {unbranded }}=6.13, \mathrm{Sd}=1.37 ; M_{\text {other-brand }}=6.16$, $\mathrm{Sd}=1.13)$. Post-hoc tests revealed no significant differences across conditions.

Plausibility check included one question adopted from Bush et al. (2008) related to the participants' confidence in their responses to the dependent variable question. The results (Figure 3) show that participants in all four conditions were very confident in their responses to the dependent variable question $\left(M_{\text {retailer }}=6.47, \mathrm{Sd}=1.08 ; M_{\text {delivery-company }}=6.43\right.$, $\left.\mathrm{Sd}=1.43 ; M_{\text {unbranded }}=6.46, \mathrm{Sd}=1.26 ; M_{\text {other-brand }}=6.29, \mathrm{Sd}=1.41\right)$. Post-hoc tests revealed no significant difference across conditions. 


\section{IJPDLM}

52,11

16

Figure 3.

Results of the post-test
Realism Check

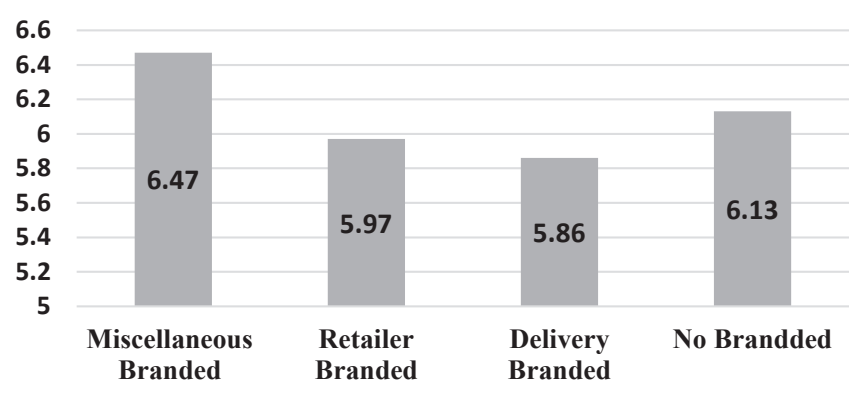

Plausibility Check

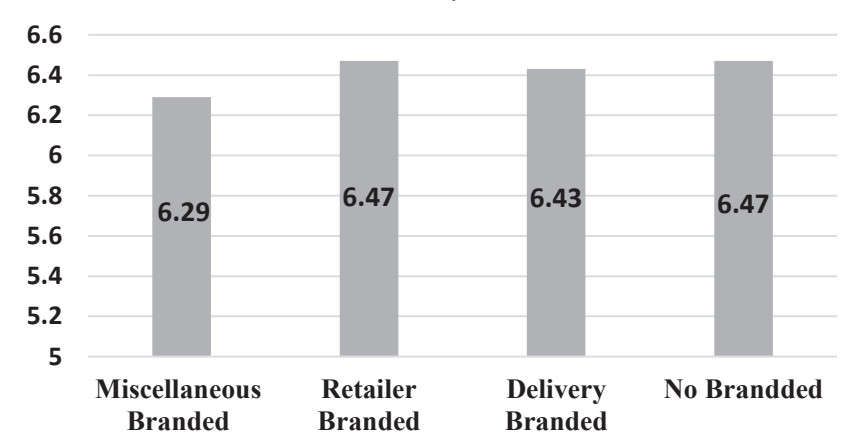

Intention to continue using home delivery service

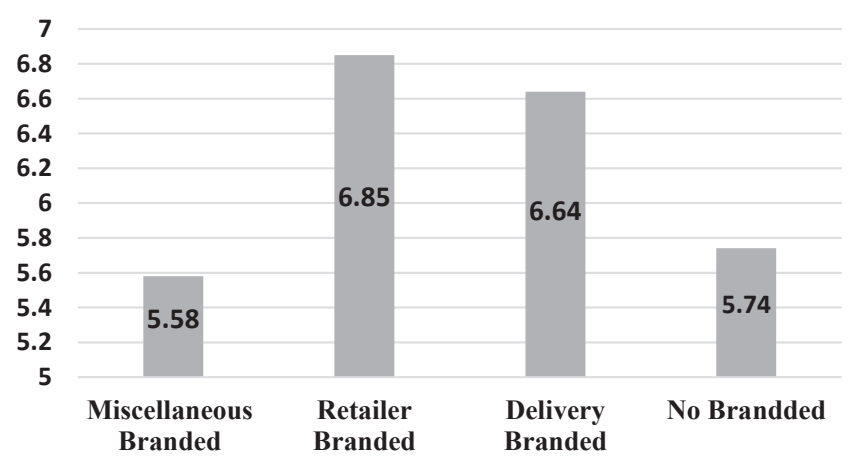

3.5.3 Alternative explanation. To rule out an alternative explanation; that the results of experiments 1 and 2 may have been due to using branded vs. unbranded modes, in the posttest, we added a fourth condition: branded delivery mode in which the brand is not clearly associated with either the retailer or a delivery company. We asked the same dependent variable question (as the one used in the main experiments) and compared the means across the conditions using ANOVA and post hoc tests (Figure 3).

The ANOVA analysis yielded a significant main effect $(F(3.76)=4.683, p<0.01)$. The pairwise comparisons confirmed that participants who had been served by either the 
unbranded delivery mode $(M=5.74, \mathrm{Sd}=1.63)$ or the branded delivery mode in which the brand was not associated with the retailer or a delivery company $(M=5.58, \mathrm{Sd}=1.02)$ were significantly less willing to continue using home delivery service after the pandemic, compared to the participants who had been served either by specialized delivery companybranded mode $(M=6.64, \mathrm{Sd}=0.69)$, or by the retailer-branded mode $(M=6.5, \mathrm{Sd}=0.95)$. All four $p$-values of these pairwise comparisons were smaller than 0.05 . We did not observe a significant difference between the retailer-branded mode and the delivery companybranded mode $(\phi>0.1)$ or between unbranded delivery mode and the branded delivery mode in which the brand was not associated with the retailer or a delivery company. These results show that merely bearing a brand logo would not affect consumers' behavioral intentions for the time after the pandemic. Therefore, we rule out the alternative explanation that the results of the main experiment may be due to using branded vs. unbranded services.

\section{General discussion}

\subsection{Theoretical implication}

Our findings contribute to the existing literature in a few ways. First, we contribute to the literature on service quality by showing that during a health crisis, consumers change their hierarchy of motivations when considering future use of home delivery services (e.g. Cronin and Taylor, 1992). In normal conditions, overall service quality scales (e.g. SERVPERF) represent a balanced combination of qualities that are almost equally weighted by consumers; therefore, such scales do predict consumers' behavioral intentions (Mentzer et al., 2001; Carrillat et al., 2007). However, during a health crisis, in line with the PMT, this uniform weighting of different aspects would not hold anymore, and consumers would prioritize hygienic quality over service quality in their decision making. By introducing perceived hygienic quality of delivery modes, as a new mediator variable, we also contribute to the research on LMD strategies (Wang et al., 2016; Esper et al., 2003). Our results demonstrate that this mediator affects the current attractiveness of alternative home delivery methods for consumers and their intentions to continue using them in the long term.

Second, we add to the emerging body of service research addressing COVID-19 pandemic and its effects on business environment (Chesbrough, 2020; Crick and Crick, 2020). Within this literature, our research is among the first to study the effect of delivery mode choice during the pandemic on consumers' post-pandemic behavioral intentions.

Third, we contribute to the research on brand visibility (Sink and Langley, 1997; Kirmani and Rao, 2000; Connelly et al., 2011; Wei and Ho, 2019) and quality signaling in service sector (Selviaridiss and Spring, 2007; Cho et al., 2008) by studying the implications of brand visibility during a pandemic. We showed that, in situations like pandemics, brand visibility can affect consumers' perceptions of service quality, and more importantly, perceptions of hygienic quality. This is consistent with the findings of Barker and Brau (2020) that consumers, especially those with low online shopping experience, use such signals as visible brands to form their perceptions of service quality.

Fourth, we introduce imprinting theory into the LMD literature, by showing that consumers with little prior experience with home delivery services need to be differentiated from frequent prior users because the latter group is likely to be already satisfied with such services and have pre-existing motivations to continue using them. The former group, on the other hand, would need additional motivation (e.g. protection motivation) to form a long-term habit. In this sense, prior infrequent users are more imprintable and suggestible towards the hygienic quality cues (Marquis and Tilcsik, 2013).

We did not find vigilance towards hygiene to be moderating the effect of perceived hygienic quality on intention to continue using home delivery services. In the first moderation 
IJPDLM 52,11

analysis we showed that, for prior frequent users, the effect of perceived hygienic quality on intention to continue using home delivery services is less pronounced. Then, we argued that during a health crisis, consumers who are vigilant towards hygiene may be still imprintable even in the case of extensive prior experience and established habits about using home delivery services. However, our results suggest that such hygiene-conscious consumers, at least in the early stages of the pandemic, are not more imprintable than other consumers. A partial explanation for this observation could be that prior frequent users of home delivery service - who may remember a history of good service provision - would be relatively forgiving regardless of vigilance towards hygiene.

Finally, by studying consumers' intention to continue using home delivery services after the pandemic, we contribute to the literature on consumers' willingness to trust service providers and remain loyal to them (Juga et al., 2010; Sugiharto et al., 2019). Hygienic quality of service as the mediator in our study, proved to be an important determinant of consumers' intention to remain loyal to a retailer after the pandemic.

In the main experiment, a single-item measure was used as the dependent variable. We acknowledge the limitations of using single-item measures in general - and do encourage others to extend our findings using multi-item measures for different aspects of behavioral intentions. However, for a concrete singular construct, such as purchase intention, using single-item measures is recommended by some scholars for the sake of clarity (Bergkvist and Rossiter, 2007). Interestingly, for such constructs, the predictive validity of the multiple-item and single-item measures may be equal (Bergkvist and Rossiter, 2007; Rossiter, 2002).

\subsection{Practical implications}

With several firms being unable to address the unexpected increase in demand during the pandemic via existing delivery modes, forming new delivery partnerships became inevitable. We argue that, retailers should explicitly show their commitment to the principles of hygiene by properly choosing delivery mode among other things. The key message for practitioners is that using a delivery agent that would carry the brand of either the retailer or a specialized delivery company would lead to an acceptable level of trust in the retailer's ability to arrange high-quality safe home deliveries. The use of unbranded delivery services would not lead to favorable consumer quality perceptions even though there may be no problem with the hygienic issues. Consequently, consumers may be less willing to continue using home delivery services of the retailers who crowd-source such services.

Therefore, when retailers are considering the upfront expenses of each delivery mode to address the extra demand during the pandemic, they should also consider the opportunities that investing in each one will bring about. More specifically, by investing in their own delivery services, or using specialized delivery service providers, retailers can improve hygienic quality perceptions and thus boost brand loyalty for prior frequent users of home delivery services as well as new customers. This may lead to a larger customer base and better economies of scale in LMD operations, further justifying their initial investment in delivery modes.

Another point worth consideration is that, although professional delivery modes (with the brand of retailer or specialized delivery company) are perceived more favorably by the consumers, it might not be feasible for all retailers to employ them during the pandemic. In such circumstances, retailers may be advised to (1) ask the unbranded carriers to temporarily use retailer-branded badges or stickers to clearly signal their association with the retailer, or (2) explicitly communicate their strict adherence to the principles of hygiene. The latter advice is based on the full mediation of the effect of delivery mode on intention to continue using home delivery services by the perceived hygienic quality.

Finally, although it may be argued that consumers' choices and preferences may not be fully stable during the pandemic, we still believe that our results provide retailers with the 
best possible hint as to the direction of consumer preferences. In the present research, we intended to provide a "point of departure" for both researchers and practitioners and motivate them to study the situation in their own industry, using similar methodologies. One should not forget that the COVID-19 pandemic - as gruesome as it is - may not be the last large-scale pandemic. The results of our research will also help retailers to identify more favorable delivery modes for the consumers in the (hopefully unlikely) future pandemics.

\section{Notes}

1. Note that in this paper delivery service and home delivery service are used interchangeably.

2. Due to the pandemic state, and the resulting lockdowns, most of the other last-mile delivery options, e.g. lockers, pick-up stores, etc., were not fully operational. Hence, in this paper, we consider home delivery as the most common/practical solution.

\section{References}

Agag, G.M. and El-Masry, A.A. (2017), "Why do consumers trust online travel websites? Drivers and outcomes of consumer trust toward online travel websites", Journal of Travel Research, Vol. 56 No. 3, pp. 347-369.

Antwi, S. (2021), "I just like this e-retailer': understanding online consumers repurchase intention from relationship quality perspective", Journal of Retailing and Consumer Services, Vol. 61, p. 102568.

Barker, J.M. and Brau, R.I. (2020), "Shipping surcharges and LSQ: pricing the last mile", International Journal of Physical Distribution and Logistics Management, Vol. 50 No. 6, pp. 667-691.

Bergkvist, L. and Rossiter, J.R. (2007), "The predictive validity of multiple-item versus single-item measures of the same constructs", Journal of Marketing Research, Vol. 44 No. 2, pp. 175-184.

Boyer, K.K. and Frohlich, M.T. (2006), "Analysis of effects of operational execution on repeat purchasing for heterogeneous customer segments", Production and Operations Management, Vol. 15 No. 2, pp. 229-242.

Boyle, M. (2020), "The U.S. is shutting down. For walmart, it's time to step up", Bloomberg Business, available at: https://www.bloomberg.com/news/articles/2020-03-17/the-nation-is-shutting-downfor-walmart-it-s-time-to-step-up.

Bush, H.F., Squire, J., Sullivan, G., Walsh, V., English, A. and Bolen, R. (2008), "An investigation of the effect of network latency on pedagogic efficacy: a comparison of disciplines", Contemporary Issues in Education Research (CIER), Vol. 1 No. 4, pp. 11-26.

Business Insider Intelligence (2019), "The crowdsourced delivery market continues to improve last mile supply chain economics in the e-commerce era", available at: https:/www.businessinsider. com/crowdsourced-delivery-report? $\mathrm{IR}=\mathrm{T}$.

Carlson, J. and O'Cass, A. (2010), "Exploring the relationships between e-service quality, satisfaction, attitudes and behaviours in content-driven e-service web sites", Journal of Services Marketing, Vol. 24 No. 2, pp. 112-127.

Carrillat, F.A., Jaramillo, F. and Mulki, J.P. (2007), "The validity of the SERVQUAL and SERVPERF scales: a meta-analytic view of 17 years of research across five continents", International Journal of Service Industry Management, Vol. 18 No. 5, pp. 472-490.

Chesbrough, H. (2020), "To recover faster from Covid-19, open up: managerial implications from an open innovation perspective", Industrial Marketing Management, Vol. 88 July, pp. 410-413.

Cho, J.J.K., Ozment, J. and Sink, H. (2008), "Logistics capability, logistics outsourcing and firm performance in an e-commerce market", International Journal of Physical Distribution and Logistics Management, Vol. 38 No. 5, pp. 336-359.

Choi, J. (2019), "Is cleanliness really a reason for consumers to revisit a hotel?", Journal of Environmental Health, Vol. 82 No. 5, pp. 16-22. 
IJPDLM 52,11

Choi, J., Nelson, D. and Almanza, B. (2019), "Food safety risk for restaurant management: use of restaurant health inspection report to predict consumers' behavioral intention”, Journal of Risk Research, Vol. 22 No. 11, pp. 1443-1457.

Chu, W., Choi, B. and Song, M. (2005), "The role of online retailer brand and infomediary reputation in increasing consumer purchase intention”, International Journal of Electronic Commerce, Vol. 9 No. 3, pp. 115-127.

Connelly, B.L., Certo, S.T., Ireland, R.D. and Reutzel, C.R. (2011), "Signaling theory: a review and assessment", Journal of Management, Vol. 37 No. 1, pp. 39-67.

Crick, J.M. and Crick, D. (2020), "Coopetition and COVID-19: 'Collaborative business-to-business marketing strategies in a pandemic crisis", Industrial Marketing Management, Vol. 78, pp. 206-213.

Cronin, J.J. Jr and Taylor, S.A. (1992), "Measuring service quality: a re-examination and extension", Journal of Marketing, Vol. 56 No. 3, pp. 55-68.

Cui, R., Li, M. and Li, Q. (2020), "Value of high-quality logistics: evidence from a clash between SF express and Alibaba", Management Science, Vol. 66 No. 9, pp. 3879-3902.

Dabholkar, P.A. (1994), "Incorporating choice into an attitudinal framework: analyzing models of mental comparison processes", Journal of Consumer Research, Vol. 22 No. 1, pp. 100-118.

Dabholkar, P.A., Thorpe, D.I. and Rentz, J.O. (1996), "A measure of service quality for retail stores: scale development and validation", Journal of the Academy of Marketing Science, Vol. 24 No. 1, p. 3.

Devari, A., Nikolaev, A.G. and He, Q. (2017), “Crowdsourcing the last mile delivery of online orders by exploiting the social networks of retail store customers", Transportation Research Part E: Logistics and Transportation Review, Vol. 105, pp. 105-122.

Doney, P.M. and Cannon, J.P. (1997), "An examination of the nature of trust in buyer-seller relationships”, Journal of Marketing, Vol. 61 No. 2, pp. 35-51.

Edelman, B.G. and Geradin, D. (2015), "Efficiencies and regulatory shortcuts: how should we regulate companies like Airbnb and Uber", Standard Technology Law Reviwed, Vol. 19, p. 293.

Eisingerich, A.B. and Bell, S.J. (2008), "Perceived service quality and customer trust: does enhancing customers' service knowledge matter?”, Journal of Service Research, Vol. 10 No. 3, pp. 256-268.

Esper, T.L., Jensen, T.D., Turnipseed, F.L. and Burton, S. (2003), "The last mile: an examination of effects of online retail delivery strategies on consumers", Journal of Business Logistics, Vol. 24 No. 2, pp. 177-203.

Fisher, J.J., Almanza, B.A., Behnke, C., Nelson, D.C. and Neal, J. (2018), "Norovirus on cruise ships: motivation for handwashing?", International Journal of Hospitality Management, Vol. 75, pp. 10-17.

Floyd, D.L., Prentice-Dunn, S. and Rogers, R.W. (2000), "A meta-analysis of research on protection motivation theory", Journal of Applied Social Psychology, Vol. 30 No. 2, pp. 407-429.

Hayes, A.F. (2017), Introduction to Mediation, Moderation, and Conditional Process Analysis: A Regression-Based Approach, 2nd ed., Guilford Publications, New York.

Heinonen, K. and Strandvik, T. (2020), "Reframing service innovation: COVID-19 as a catalyst for imposed service innovation", Journal of Service Management, Vol. 32 No. 1, pp. 101-112.

Hellier, P.K., Geursen, G.M., Carr, R.A. and Rickard, J.A. (2003), "Customer repurchase intention: a general structural equation model”, European Journal of Marketing, Vol. 37 Nos 11/12, pp. 1762-1800.

Huang, Y.K., Feng, C.M. and Wu, P.J. (2009), "A structural equation model of management strategies and firm performance: a case study of logistics service quality on home delivery", International Journal of Electronic Customer Relationship Management, Vol. 3 No. 3, pp. 281-300.

Jarvenpaa, S.L., Tractinsky, N. and Vitale, M. (2000), "Consumer trust in an Internet store", Information Technology and Management, Vol. 1 Nos 1-2, pp. 45-71. 
Jie, Y.U., Subramanian, N., Ning, K. and Edwards, D. (2015), "Product delivery service provider selection and customer satisfaction in the era of internet of things: a Chinese e-retailers' perspective", International Journal of Production Economics, Vol. 159, pp. 104-116.

Juga, J., Juntunen, J. and Grant, D.B. (2010), "Service quality and its relation to satisfaction and loyalty in logistics outsourcing relationships", Managing Service Quality: An International Journal, Vol. 20 No. 6, pp. 496-510.

Kalyanam, K. and McIntyre, S. (2002), "The e-marketing mix: a contribution of the e-tailing wars", Journal of the Academy of Marketing Science, Vol. 30 No. 4, pp. 487-499.

Kaswengi, J. and Lambey-Checchin, C. (2019), "How logistics service quality and product quality matter in the retailer-customer relationship of food drive-throughs: the role of perceived convenience", International Journal of Physical Distribution and Logistics Management, Vol. 50 No. 5, pp. 535-555.

Kirmani, A. and Akshay, R. (2000), "No pain, no gain: a critical review of the literature on signaling unobservable product quality”, Journal of Marketing, Vol. 64 No. 2, pp. 66-79.

Kumar, R. and Kumar, U. (2004), "A conceptual framework for the development of a service delivery strategy for industrial systems and products", Journal of Business and Industrial Marketing, Vol. 19 No. 5, pp. 310-319.

Kunze, O. (2016), "Replicators, ground drones and crowd logistics a vision of urban logistics in the year 2030", Transportation Research Procedia, Vol. 19, pp. 286-299.

Lebeau, P., De Cauwer, C., Van Mierlo, J., Macharis, C., Verbeke, W. and Coosemans, T. (2015), "Conventional, hybrid, or electric vehicles: which technology for an urban distribution Centre?", Science World Journal, Vol. 2015, pp. 1-11.

Lemon, K.N. and Verhoef, P.C. (2016), "Understanding customer experience throughout the customer journey”, Journal of Marketing, Vol. 80 No. 6, pp. 69-96.

Li, H., Fang, Y., Wang, Y., Lim, K.H. and Liang, L. (2015), "Are all signals equal? Investigating the differential effects of online signals on the sales performance of e-marketplace sellers", Information Technology and People, Vol. 28 No. 3, pp. 699-723.

Lim, S.F.W., Jin, X. and Srai, J.S. (2018), “Consumer-driven e-commerce”, International Journal of Physical Distribution and Logistics Management, Vol. 48 No. 3, pp. 308-332.

Maddux, J.E. and Rogers, R.W. (1983), "Protection motivation and self-efficacy: a revised theory of fear appeals and attitude change", Journal of Experimental Social Psychology, Vol. 19 No. 5, pp. 469-479.

Mangiaracina, R., Perego, A., Seghezzi, A. and Tumino, A. (2019), "Innovative solutions to increase last-mile delivery efficiency in B2C e-commerce: a literature review", International Journal of Physical Distribution and Logistics Management, Vol. 49 No. 9, pp. 901-920.

Marquis, C. and Tilcsik, A. (2013), "Imprinting: toward a multilevel theory", Academy of Management Annals, Vol. 7 No. 1, pp. 195-245.

Melton, J. (2020), “Grocery retailers adapt as coronavirus upends shopping patterns”, Digital Commerce 360, available at: https://www.digitalcommerce360.com/article/coronavirus-impact-online-retail/.

Mensah, I. and Mensah, R.D. (2018), "Effects of service quality and customer satisfaction on repurchase intention in restaurants on university of cape coast campus", Journal of Tourism, Heritage and Services Marketing, Vol. 4 No. 2, pp. 27-36.

Mentzer, J.T., Flint, D.J. and Hult, G.T.M. (2001), "Logistics service quality as a segment-customized process", Journal of Marketing, Vol. 65 No. 4, pp. 82-104.

Milne, S., Sheeran, P. and Orbell, S. (2000), "Prediction and intervention in health-related behavior: a meta-analytic review of protection motivation theory", Journal of Applied Social Psychology, Vol. 30 No. 1, pp. 106-143.

Morash, E.A., Dröge, C. and Vickery, S. (1996), "Boundary-spanning interfaces between logistics, production, marketing and new product development", International Journal of Physical Distribution and Logistics Management, Vol. 26 No. 8, pp. 43-62. 
IJPDLM 52,11

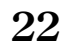

Murfield, M., Boone, C.A., Rutner, P. and Thomas, R. (2017), "Investigating logistics service quality in omni-channel retailing", International Journal of Physical Distribution and Logistics Management, Vol. 47 No. 4, pp. 263-296.

Ogden, J. and Hills, L. (2008), "Understanding sustained behavior change: the role of life crises and the process of reinvention”, Health, Vol. 12 No. 4, pp. 419-437.

Peer, E., Brandimarte, L., Samat, S. and Acquisti, A. (2017), "Beyond the Turk: alternative platforms for crowdsourcing behavioral research", Journal of Experimental Social Psychology, Vol. 70, pp. 153-163.

Render, B. and O'Connor, T.S. (1976), "The influence of price, store name and brand name on perception of product quality", Journal of the Academy of Marketing Science, Vol. 4 Fall, pp. 722-730.

Rigby, C. (2020), "Coronavirus round-up: supermarkets expand delivery capability fast, plus debenhams, ScS, WH smith, John Lewis and the ONS on covid-19", Internet Retailing Covid19 Coverage, available at: https://internetretailing.net/covid-19/covid-19/updated-coronavirusround-up-supermarkets-expand-delivery-capability-fast-plus-debenhams-scs-wh-smith-johnlewis-and-the-ons-on-covid-19-21213.

Rogers, R.W. (1975), “A protection motivation theory of fear appeals and attitude changel”, The Journal of Psychology, Vol. 91 No. 1, pp. 93-114.

Rosen, L.D. and Karwan, K.R. (1994), "Prioritizing the dimensions of service quality: an empirical investigation and strategic assessment”, International Journal of Service Industry Management, Vol. 5 No. 4, pp. 39-52.

Rossiter, J.R. (2002), "The C-OAR-SE procedure for scale development in marketing”, International Journal of Research in Marketing, Vol. 19, pp. 305-335.

Sahin, A., Zehir, C. and Kitapci, H. (2012), "The effects of brand experience and service quality on repurchase intention: the role of brand relationship quality", African Journal of Business Management, Vol. 6 No. 45, p. 11190.

Selviaridiss, K. and Spring, M. (2007), "Third party logistics: a literature review and research agenda", The International Journal of Logistics Management, Vol. 18 No. 1, pp. 125-150.

Sheth, J. (2020), “Impact of Covid-19 on consumer behavior: will the old habits return or die?", Journal of Business Research, Vol. 117, pp. 280-283.

ShipBob's daily statistics (2020), "Daily ecommerce sales trends and resources", available at: https:// trends.shipbob.com/\#lp-pom-block-1531

Sink, H.L. and Langley, C.J. Jr (1997), "A managerial framework for the acquisition of third-party logistics services", Journal of Business Logistics, Vol. 18 No. 2, p. 163.

Sugiharto, H.T., Zein, S.R., Setiawan, E.B. and Lesmini, L. (2019), "Increasing purchase intention through delivery and brand reputation in E-commerce", Advances in Transportation and Logistics Research, Vol. 2, pp. 51-58.

Thirumalai, S. and Sinha, K.K. (2005), "Customer satisfaction with order fulfillment in retail supply chains: implications of product type in electronic B2C transactions", Journal of Operations Management, Vol. 23 Nos 3-4, pp. 291-303.

Vakulenko, Y., Shams, P., Hellström, D. and Hjort, K. (2019), "Online retail experience and customer satisfaction: the mediating role of last mile delivery", The International Review of Retail, Distribution and Consumer Research, Vol. 29 No. 3, pp. 306-320.

Vazquez-Noguerol, M., Comesaña-Benavides, J., Poler, R. and Prado-Prado, J.C. (2020), "An optimisation approach for the e-grocery order picking and delivery problem", Central European Journal of Operations Research, pp. 1-30.

Venkatesh, V., Morris, M.G., Davis, G.B. and Davis, F.D. (2003), "User acceptance of information technology: toward a unified view", MIS Quarterly, pp. 425-478. 
Vilnai-Yavetz, I. and Gilboa, S. (2010), "The effect of servicescape cleanliness on customer reactions", Services Marketing Quarterly, Vol. 31 No. 2, pp. 213-234.

Vos, M.C., Galetzka, M., Mobach, M.P., van Hagen, M. and Pruyn, A.T. (2019), "Measuring perceived cleanliness in service environments: scale development and validation", International Journal of Hospitality Management, Vol. 83, pp. 11-18.

Wang, Y., Zhang, D., Liu, Q., Shen, F. and Lee, L.H. (2016), "Towards enhancing the last-mile delivery: an effective crowd-tasking model with scalable solutions", Transportation Research Part E: Logistics and Transportation Review, Vol. 93, pp. 279-293.

Wei, C.L. and Ho, C.T. (2019), "Exploring signaling roles of service providers' reputation and competence in influencing perceptions of service quality and outsourcing intentions", Journal of Organizational and End User Computing (JOEUC), Vol. 31 No. 1, pp. 86-109.

Wolfinbarger, M. and Gilly, M.C. (2003), "eTailQ: dimensionalizing, measuring and predicting etail quality”, Journal of Retailing, Vol. 79 No. 3, pp. 183-198.

$\mathrm{Yu}$, J., Seo, J. and Hyun, S.S. (2021), "Perceived hygiene attributes in the hotel industry: customer retention amid the COVID-19 crisis", International Journal of Hospitality Management, Vol. 93, p. 10278.

\section{Appendix}

\section{The scenarios used in the experiments}

In the first section, you will be presented with a scenario. All the questions that follow are about this scenario. Please read through it very carefully and imagine being in the described situation:

It is in the middle of the lockdown period caused by the coronavirus pandemic. Yesterday, you visited the online store of the local retailer chain and bought a few items to be home-delivered to your address next business day (today).

\section{Condition 1: retailer-branded delivery partner}

Today, they gave you a message for the delivery, and a few minutes later, a van bearing the logo of the retailer appeared in front of your apartment. Then, a woman, who appeared to be an employee of the retailer by her uniform, greeted you from the recommended distance and left the package (your order) for you to pick up. The package contained the items you had bought.

\section{Condition 2: delivery company-branded partner}

Today, they gave you a message for the delivery and a few minutes later a van bearing the logo of a package-delivery company appeared in front of your apartment. Then, a woman, who appeared to be an employee of the package-delivery company by her uniform, greeted you from the recommended distance and left the package (your order) for you to pick up. The package contained the items you had bought.

\section{Condition 3: unbranded delivery partner}

Today, they gave you a message for the delivery and a few minutes later a van appeared in front of your apartment. Then, a woman in normal dresses, greeted you from the recommended distance and left the package (your order) for you to pick up. The package contained the items you had bought.

\section{Condition 4 (only in the post-test): miscellaneous-branded delivery partner}

Today, they gave you a message for the delivery and a few minutes later a van appeared in front of your apartment. The van had the logo of a company on it, but you could not recognize the company (it was not the logo of the pharmacy or a well-known package delivery company). Then, a woman, who appeared to be an employee of the same company by her uniform, greeted you from the recommended distance and left the package (your order) for you to pick up. The package contained the items you had bought. 
IJPDLM

52,11

\section{4}

\section{About the authors}

Reza Movarrei is a postdoctoral researcher at the Centre for Relationship Marketing and Service Management (CERS), Hanken School of Economics, Finland. He received his PhD in Marketing (2017) from Grenoble Ecole de Management, France. Reza Movarrei is the corresponding author and can be contacted at: reza.movarrei@hanken.fi

Sara Rezaee Vessal is an assistant professor of Operations Management Department at ESSEC Business School. Her research focuses on collaboration within and between firms in the context of new product development, socially responsible supply chain and production decisions. She received her $\mathrm{PhD}$ in Supply Chain Management (2017) from HEC Paris.

Saeedeh Rezaee Vessal is an associate professor of Marketing at Paris School of Business. She received her $\mathrm{PhD}$ in Marketing (2018) from Grenoble Alpes University. Her research focuses on experimental social psychology and consumer decision making.

Jaakko Aspara is a full professor of Marketing at NEOMA Business School, France. He received his $\mathrm{PhD}$ in Economics and Business Administration (2007) from Helsinki School of Economics and his Doctor of Arts in Industrial Design (2009) from University of Art and Design Helsinki.

For instructions on how to order reprints of this article, please visit our website: www.emeraldgrouppublishing.com/licensing/reprints.htm Or contact us for further details: permissions@emeraldinsight.com 